\title{
Leriche Syndrome Detected by 64-MDCT
}

\author{
Kenji Norimatsu, Yuhei Shiga, Shin-ichiro Miura and Keijiro Saku
}

Key words: aortoiliac occlusive disease, 64-multidetector row computed tomography, calcification

(Intern Med 50: 1263, 2011)

(DOI: 10.2169/internalmedicine.50.5441)

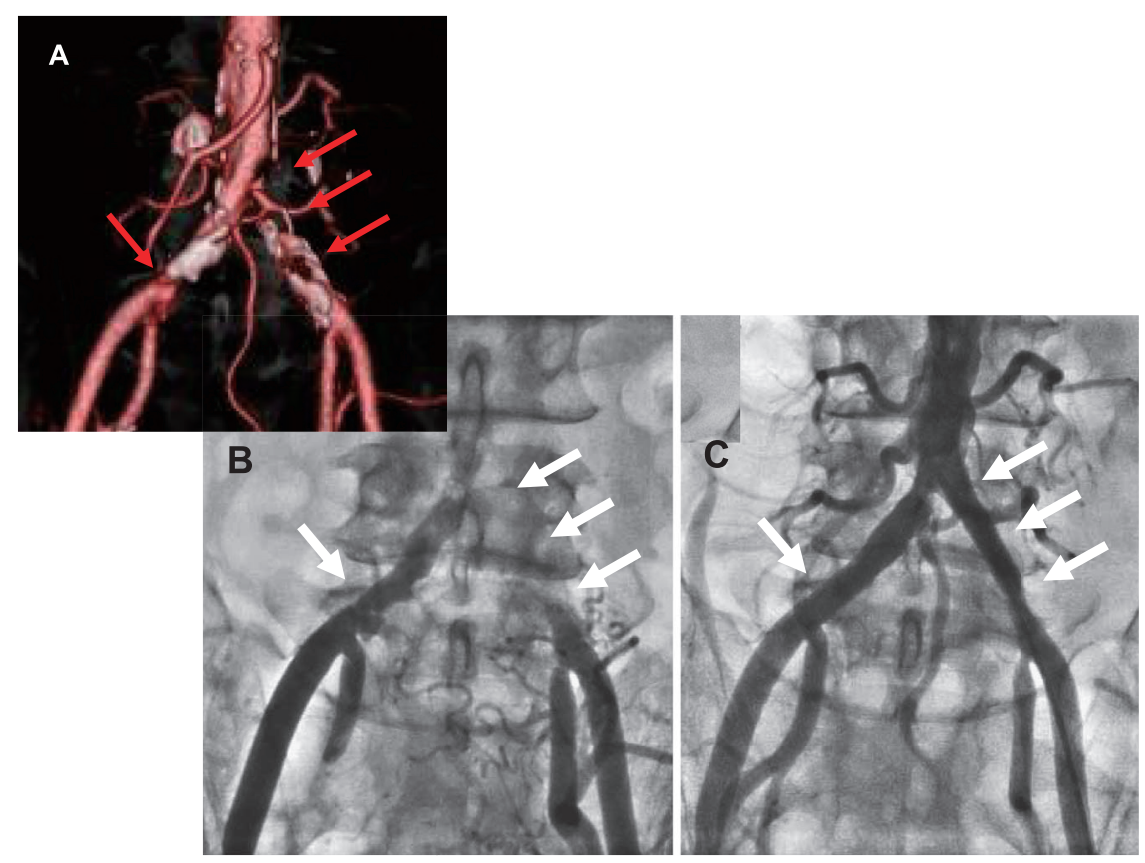

Picture 1.

Aortoiliac occlusive disease, also known as Leriche syndrome, is an atherosclerotic occlusive disease involving the abdominal aorta and/or both of the iliac arteries (1). A 52year-old man had a complaint of progressive intermittent claudication. His femoral pulses were diminished, and the ankle-brachial index (ABI) was reduced (Rt. 0.85 and Lt. 0.72). He had a history of hypertension and smoking, but not dyslipidemia or diabetes mellitus. The volume-rendered image by 64-multidetector row computed tomography (64MDCT) showed severe stenoses from the abdominal aorta to bilateral common iliac arteries with heavy calcification (Picture 1A). The incidence of his symptom increased and the condition of erectile dysfunction appeared. Furthermore, aor- tic angiography showed severe stenosis in the right common iliac artery and complete occlusion of the left common iliac artery with some collaterals (Picture 1B). After percutaneous transluminal angioplasty (Picture 1C), he had no symptoms and his ABI became elevated (Rt. 1.02 and Lt. 1.01).

The authors state that they have no Conflict of Interest (COI).

\section{Reference}

1. Leriche R, Morel A. The syndrome of thrombotic obliteration of the aortic bifurcation. Ann Surg 127: 193-206, 1948.

Department of Cardiology, Fukuoka University School of Medicine, Japan

Received for publication March 3, 2011; Accepted for publication March 7, 2011

Correspondence to Dr. Shin-ichiro Miura, miuras@cis.fukuoka-u.ac.jp

(C) 2011 The Japanese Society of Internal Medicine Journal Website: http://www.naika.or.jp/imindex.html 